\title{
High Temperature Exposure of HPC - Experimental Analysis of Residual Properties and Thermal Response
}

\author{
Zbyšek Pavliki, a, Jan Fořt ${ }^{1}$, Milena Pavlíková ${ }^{1}$, Jaroslav Pokorný ${ }^{1}$, Anton Trník ${ }^{1}$, Jiří Studnička $^{1}$, David Čítek², Jiři Kolísko \\ and Robert Černý ${ }^{1}$ \\ ${ }^{1}$ Department of Materials Engineering and Chemistry, Faculty of Civil Engineering, CTU Prague, Thákurova 7, 16629 Prague, Czech \\ Republic \\ ${ }^{2}$ Department of Experimental methods, Klokner Institute, CTU Prague, Šolínova 7, 16608 Prague, Czech Republic
}

\begin{abstract}
The effect of high temperature exposure on properties of a newly designed High Performance Concrete (HPC) is studied in the paper. The HPC samples are exposed to the temperatures of $200,400,600,800$, and $1000^{\circ} \mathrm{C}$ respectively. Among the basic physical properties, bulk density, matrix density and total open porosity are measured. The mechanical resistivity against disruptive temperature action is characterised by compressive strength, flexural strength and dynamic modulus of elasticity. To study the chemical and physical processes in HPC during its hightemperature exposure, Simultaneous Thermal Analysis (STA) is performed. Linear thermal expansion coefficient is determined as function of temperature using thermodilatometry (TDA). In order to describe the changes in microstructure of HPC induced by high temperature loading, MIP measurement of pore size distribution is done. Increase of the total open porosity and connected decrease of the mechanical parameters for temperatures higher than $200{ }^{\circ} \mathrm{C}$ were identified.
\end{abstract}

\section{Introduction}

The population boom and building grounds limitations is reflected in construction of high-rise buildings. Hence, normal strength concrete is often replaced by the high performance concrete (HPC) or ultra-high performance concrete (UHPC). The use of HPC for high rise building application creates tasks for the assessment its load carrying capacity and behaviour during exposure to high temperatures when damage of chemical and structural changes takes place. In order to uplift HPC mechanical parameters, decrease of the water cement ratio and application of superplasticizers are common procedure. Due to the lower dosage of batch water, the pore volume decreases what results in improved mechanical strength of concrete. Despite of these improvements, decrease of the pore volume leads to the decrease of the concrete fire resistance.

High temperature exposure, especially rapid temperature rise connected to the fire, can cause serious damage in micro and meso structure of concrete [1]. Concrete spalling and consequent bar exposure decrease durability of such structures. The fire exposure generates increase of the compressive stress parallel to the exposed surface causing tensile stress upright to the heated surface due to the thermal expansion of the water inside the pores [2-3]. Hence, the increase of the temperature builds up the water vapour pressure in the concrete pores and tensile stress in concrete structure. The different mechanisms of spalling were described by Sanchayan and Foster [4] and many parameters influencing spalling were discussed. However, prediction of the spalling represents complex task for further evaluation. A spalling is usually sorted into following categories: aggregate spalling, explosive spalling, surface spalling and corner spalling [5-6]. The first three types of spalling occur during first 20-30 minutes of fire exposure. The corner spalling arises after 30-60 minutes of fire [7].

Properties such a compressive strength, flexure strength and modulus of elasticity are usually studied in relation with the high temperature exposure. In the study of Hertz [8], free water content, moisture gradient and its influence in case of elevated temperature exposal was examined and found as a reason of spalling. Studies $[2,5]$ focused on an estimation of the critical amount of water in concrete concluded that moisture about less than 3 mass $\%$ will not cause spalling. The range of 3-4 mass $\%$ of free water generates risk of explosive spalling in dependence on the concrete microstructure [4]. Unfortunately, $\mathrm{Fu}$ and $\mathrm{Li}$ [9] found that for microstructure of the HPC or UHPC with very small pores and permeability, moisture content slightly higher than zero can cause spalling.

In case of fire, the release of the bound water from the calcium silicate hydrates (CSHs) takes place at about $110-150{ }^{\circ} \mathrm{C}[10]$. Increase of the tensile stresses in the

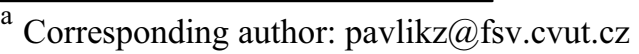


concrete structure is caused by the thermal expansion of the aggregates from $300{ }^{\circ} \mathrm{C}$, where some cracks appearance was noted [11]. This explains the fact that only negligible decrease of the concrete mechanical parameters under $300{ }^{\circ} \mathrm{C}$ is usually observed. The decomposition of the $\mathrm{Ca}(\mathrm{OH})_{2}$ can reduce the durability of the concrete in case of rehydration of the lime as a consequence of the cooling of the concrete after high temperature exposure. Here, surface cracking and spalling may arise. The $\mathrm{C}-\mathrm{S}-\mathrm{H}$ decomposition starts at about $550{ }^{\circ} \mathrm{C}$ but became significant only above $600{ }^{\circ} \mathrm{C}$. The decomposition rate increases dramatically with temperature above $600{ }^{\circ} \mathrm{C}$ and it is a main reason for the strength loss of concrete exposed to temperatures above $600{ }^{\circ} \mathrm{C}$ [12-13] The main products of the C-S-H decomposition are $\mathrm{C}_{3} \mathrm{~S}$ and $\beta-\mathrm{C}_{2} \mathrm{~S}$ (decomposes at about $650{ }^{\circ} \mathrm{C}$ ). Significant loss of concrete durability, strength and other structural changes occur at temperatures higher than $600{ }^{\circ} \mathrm{C}$ [14]. Temperature about $800{ }^{\circ} \mathrm{C}$ is responsible for the concrete crumbling and temperature above $1150{ }^{\circ} \mathrm{C}$ turn minerals into the glassy phase.

\section{Experimental}

Newly developed HPC composed of Portland cement CEM I 42.5, silica sand with maximum size of $2 \mathrm{~mm}$, mineral microfillers, and water was examined. In order to decrease the amount of the batch water, the superplasticizer based on polycarboxylate ether was used for reaching the proper workability of fresh mixture and for decrease of concrete porosity. The detailed composition of studied concrete is shown in Table 1.

Table 1. Composition of researched HPC.

\begin{tabular}{|l|c|}
\hline Material & Amount $[\mathbf{k g}]$ \\
\hline Silica sand $0-2 \mathrm{~mm}$ & 1160 \\
\hline CEM I 42.5 R & 700 \\
\hline Mineral fillers & 250 \\
\hline Superplasticizer & 30 \\
\hline Water & 160 \\
\hline
\end{tabular}

\subsection{Sampling and curing}

HPC prisms having dimensions of $40 \times 40 \times 160 \mathrm{~mm}$ were casted, cured for 24 hours in highly humid environment of approx. $98 \%$ and after removing from forms placed for 27 days in water having temperature of approx. $20^{\circ} \mathrm{C}$.

The cured samples were before the particular tests dried for 72 hours at $105{ }^{\circ} \mathrm{C}$. In order to evaluate the effect of high temperature exposure on HPC properties, the samples were exposed 2 hours to the temperatures of 200, 400, 600, 800, and $1000{ }^{\circ} \mathrm{C}$ respectively. The applied heating rate was $1^{\circ} \mathrm{C} / \mathrm{min}$.

\subsection{Basic physical properties}

Among the basic physical properties, bulk density, matrix density, and total open porosity were measured. The bulk density measurement was performed by weighting the sample dry mass and measurement of its volume by the digital caliper. The matrix density was accessed by a helium pycnometer (Pycnomatic ATC, Thermo Scientific) and the total open porosity was calculated on the basis of knowledge of the bulk and matrix density according to the formula

$$
\phi=1-\frac{\rho_{\text {bulk }}}{\rho_{\text {matrix }}},
$$

where $\phi[-]$ is the total open porosity, $\rho_{\text {bulk }}\left[\mathrm{kg} / \mathrm{m}^{3}\right]$ the bulk density and $\rho_{\text {mat }}\left[\mathrm{kg} / \mathrm{m}^{3}\right]$ the matrix density [15]. The relative expanded uncertainty of applied testing method was $5 \%$.

\subsection{Mechanical parameters}

Mechanical resistivity of tested HPC was characterized by flexural strength, compressive strength and dynamic modulus of elasticity measurement. The flexural strength was determined according to the procedure described in the technical standard C CSN EN 12390-5 - Testing hardened concrete - Part 5: Flexural strength of test specimens. For the measurement, prismatic samples having dimensions of $40 \times 40 \times 160$ $\mathrm{mm}$ were used. The compressive strength was measured according to the standard ČSN EN 12390-3 - Testing hardened concrete - Part 3: Compressive strength of test specimens. The experiments were done on the halves of broken prisms in the flexural strength test; the loading area was $40 \times 40 \mathrm{~mm}$. The uncertainty of both testing methods is $1.4 \%$. The dynamic Young's modulus was measured by the pulse ultrasonic method using a DIO 562 device working on the frequency of $50 \mathrm{kHz}$ [16].

\subsection{Thermodilatometry (TDA)}

Thermal stability of the studied HPC was investigated by a horizontal thermodilatometer allowing monitoring of the length changes of a studied material during a negligible loading as a function of temperature and time. The samples with the dimensions of $20 \times 20 \times 160 \mathrm{~mm}$ were examined in the temperature interval from 25 to $1000{ }^{\circ} \mathrm{C}$ with a heating rate $1{ }^{\circ} \mathrm{C} / \mathrm{min}$ in a static air atmosphere. From the measured temperature induced length changes, linear thermal expansion coefficient was accessed as function of temperature $\alpha(T)$ according to the following equation

$$
\alpha=\frac{d\left(l / l_{0}\right)}{d T}=\frac{d \varepsilon}{d T},
$$

where $\alpha\left[1 /{ }^{\circ} \mathrm{C}\right]$ is the linear thermal expansion coefficient, $l[\mathrm{~m}]$ the sample length at chosen temperature, $l_{0}[\mathrm{~m}]$ the initial sample length, $\varepsilon[-]$ the thermal strain. 
This analysis was performed using apparatus Labsys Evo (Setaram) that allows simultaneous DSC-TG measurements [17-18]. For our measurements, finely ground samples were prepared and placed into an alumina crucible with a volume of $100 \mathrm{~mm}^{3}$. The mass of the samples was about $80 \mathrm{mg}$. The STA was realized in the temperature range from 25 to $1200{ }^{\circ} \mathrm{C}$ with a heating rate of $5{ }^{\circ} \mathrm{C} / \mathrm{min}$ in an argon atmosphere (flow rate 40 $\mathrm{ml} / \mathrm{min})$.

\subsection{Mercury intrusion porosimetry (MIP)}

The effect of elevated temperatures on changes in porous structure of studied HPC was observed using MIP analysis. For the measurement, the combination of porosimeters Pascal 140 and Pascal 440 (Thermo Scientific) was used. At the evaluation of the measured data, the circular cross section of capillaries was assumed. The mercury contact angle was assumed to be $130^{\circ}$.

\section{Results and discussion}

Basic physical and mechanical properties of the tested HPC are given in Tables 2-3.

Table 2. Basic physical properties of HPC.

\begin{tabular}{|c|c|c|c|}
\hline $\begin{array}{c}\text { Temperature } \\
{\left[{ }^{\circ} \mathbf{C}\right]}\end{array}$ & $\begin{array}{c}\text { Bulk } \\
\mathbf{d e n s i t y} \\
{\left[\mathbf{k g} / \mathbf{m}^{3}\right]}\end{array}$ & $\begin{array}{c}\text { Matrix } \\
\mathbf{d e n s i t y} \\
{\left[\mathbf{k g} / \mathbf{m}^{3}\right]}\end{array}$ & $\begin{array}{c}\text { Total open } \\
\text { porosity } \\
{[\%]}\end{array}$ \\
\hline reference & 2349 & 2554 & 7.8 \\
\hline 200 & 2363 & 2561 & 7.3 \\
\hline 400 & 2156 & 2667 & 16.2 \\
\hline 600 & 2130 & 2670 & 17.3 \\
\hline 800 & 2111 & 2924 & 25.9 \\
\hline 1000 & 2075 & 2920 & 29.4 \\
\hline
\end{tabular}

Table 3. Mechanical parameters of HPC.

\begin{tabular}{|c|c|c|c|}
\hline $\begin{array}{c}\text { Temperature } \\
{\left[{ }^{\circ} \mathbf{C}\right]}\end{array}$ & $\begin{array}{c}\text { Flexural } \\
\text { strength } \\
{[\mathbf{M P a}]}\end{array}$ & $\begin{array}{c}\text { Compressive } \\
\text { strength } \\
{[\mathbf{M P a}]}\end{array}$ & $\begin{array}{c}\text { Young's } \\
\text { Modulus } \\
{[\mathbf{G P a}]}\end{array}$ \\
\hline reference & 11.1 & 113.8 & 45.9 \\
\hline 200 & 13.7 & 123.8 & 47.2 \\
\hline 400 & 6.3 & 105.2 & 39.2 \\
\hline 600 & 3.7 & 75.8 & 30.2 \\
\hline 800 & 2.4 & 50.6 & 23.6 \\
\hline 1000 & 1.6 & 20.5 & 13.1 \\
\hline
\end{tabular}

Here, the presented results were calculated on the basis of five independent measurements on different samples.
According to the ČSN EN 12390-5, the flexural strength data is calculated from the three independent measurements and compressive strength from the six.

For samples exposed to the maximum temperature of $200{ }^{\circ} \mathrm{C}$, decrease of the total open porosity value and related increase in mechanical strength was observed. Up to this temperature, only minor changes in concrete structure were monitored and the thermal strain led to the limited improvement of the mechanical parameters.

Decrease of the bulk density and consequent increase of the total open porosity are distinct in relation to the temperatures higher than $200{ }^{\circ} \mathrm{C}$. These can be attributed to the structural changes in concrete matrix due to the high temperature action. One can also observe decrease in the strength characteristics of the same trend as changes in the porosity. The significant decrease of the compressive strength was visible at $600{ }^{\circ} \mathrm{C}$, where approx. $30 \%$ drop occurred.

The above given findings are similar to the conclusions of the study published by Netinger et al. [19], where only slight mechanical changes were observed up to $500{ }^{\circ} \mathrm{C}$. Starting from $600{ }^{\circ} \mathrm{C}$, the mechanical characteristics decreased proportionally with increasing temperature. The temperature of $1000{ }^{\circ} \mathrm{C}$ caused an almost complete loss of mechanical parameters of HPC.

Data obtained by the MIP given in Figure 1 confirmed that the temperature loading influenced the total open porosity as well as diameter of pores. While differences between the pore size distributions of reference sample and sample exposed to $200^{\circ} \mathrm{C}$ were almost negligible, the temperature exposure of $400{ }^{\circ} \mathrm{C}$ shift distinctly the pore size distribution curve due to the increase of pore volume. Concurrently, the increased total open porosity has negative effect on the mechanical parameters. Similar finding was observed for every increase of temperature up to $1000{ }^{\circ} \mathrm{C}$, which significantly increased the total open porosity as well as pore diameter.

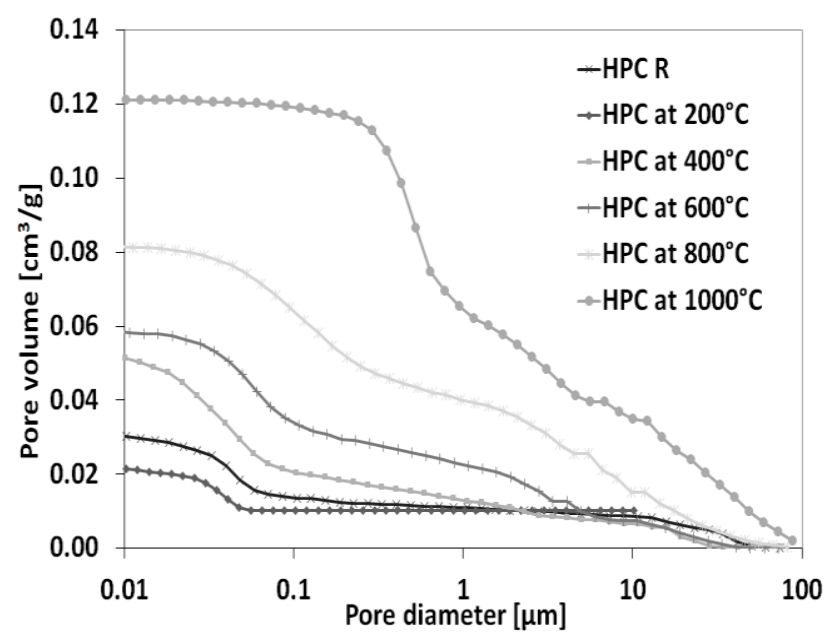

Figure 1. Cumulative pore volume. 


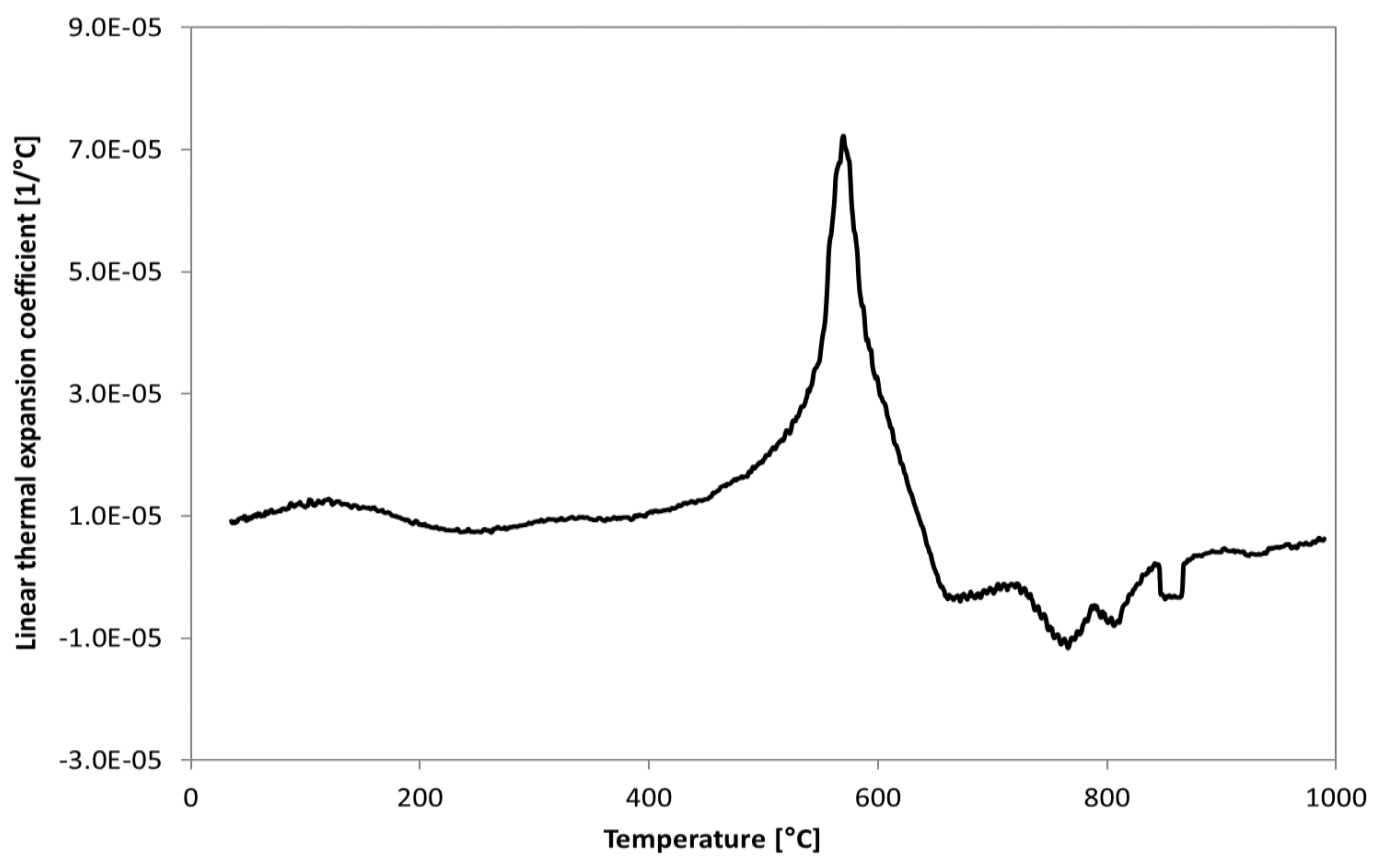

Figure 2. Linear thermal expansion coefficient.

The temperature dependent linear thermal expansion coefficient is presented in Figure 2. The distinct thermal strain we assign to the two main changes in the concrete matrix. The first is the decomposition of portlandite usually connected with the cracks formation. The change in the crystal phase of the aggregate, i.e. the transformation of the alpha quartz to the beta quartz modification, is the second phenomena responsible for the linear thermal expansion of the studied material.

In the temperature interval from 573 to $\sim 650{ }^{\circ} \mathrm{C}$, no significant expansion was observed and the studied material even underwent limited thermal shrinkage. The shrinkage recorded at the temperature of about $700-750{ }^{\circ} \mathrm{C}$ was found by Estevez [20] and can be assigned to the formation of the new silica compound.

The thermal strain data is shown in Figure 3. It reveals the increase of the strain in the dependency on the increasing temperature up to $600{ }^{\circ} \mathrm{C}$. The subsequent decrease of the strain, visible from 650 to $850{ }^{\circ} \mathrm{C}$ is the result of the reaction of the silica microfillers to the high temperature exposure as was mentioned above.

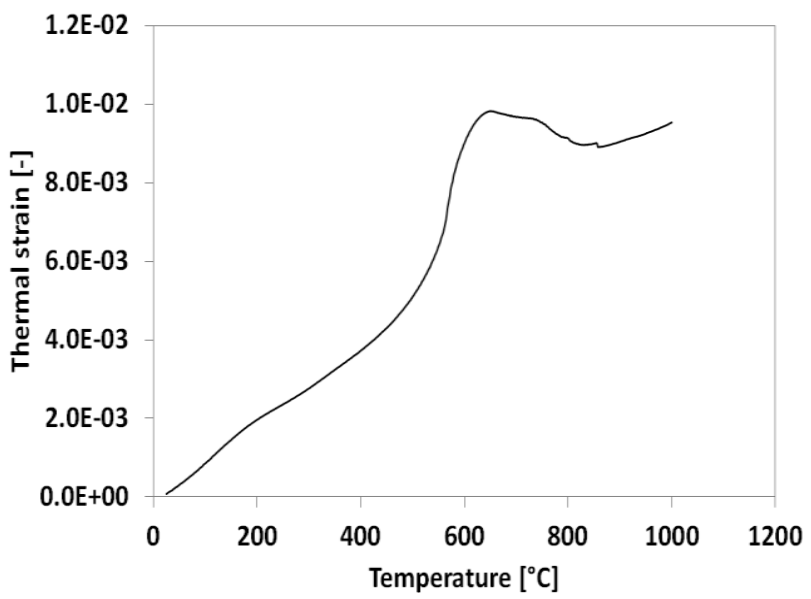

Figure 3. Thermal strain.
The data obtained by STA is shown in Figure 4. Here, information about decomposition and crystallization in the studied HPC during the high temperature exposure are accessed. The release of the bound water from pores due to the dehydration and loss of water from C-S-H gels took place in the temperature interval from 20 to $200^{\circ} \mathrm{C}$. The decomposition of the ettringite was recorded at the same temperature interval. The portlandite $\mathrm{Ca}(\mathrm{OH})_{2}$ disintegration was found at $445{ }^{\circ} \mathrm{C}$. The temperature about $573{ }^{\circ} \mathrm{C}$ is typical for transformation of the quartz from the alpha to the beta modification. This reaction is connected with volume expansion, sharp endothermic heat flow peak and no mass change. In the temperature interval $580-800{ }^{\circ} \mathrm{C}$, the calcite decomposition took place. At the temperature above $800{ }^{\circ} \mathrm{C}$, there was found one significant exothermal peak corresponding to a crystallization process. In our study, this peak corresponds to the crystallization of wollastonite [21].

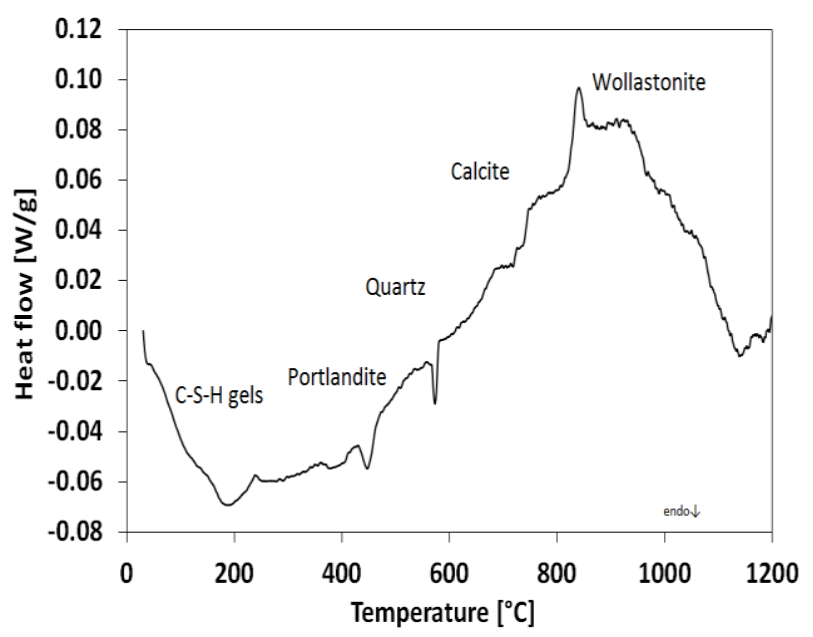

Figure 4. DSC data of the studied HPC. 


\section{Conclusions}

The residual properties of HPC after high temperature exposure and its performance during the high temperature action were studied. Increase of the total open porosity and connected decrease of the mechanical parameters for temperatures higher than $200{ }^{\circ} \mathrm{C}$ were identified. This concrete performance was explained by STA data that allowed identification of transformation and decomposition of the hydrated products in the HPC matrix. The temperature of the dehydratation of the physically bonded water and $\mathrm{C}-\mathrm{S}-\mathrm{H}$ gels, portlandite decomposition, ettringite dehydration, trasformation of the alpha quartz to the beta modification, calcite disintegration, wollastonite crystallization and microsilica transformation were revealed and documented.

Obtained results will be employed for further research aimed at the formulation of the computational model for prediction of the HPC structures behavior exposed to the fire and high temperature action.

\section{Acknowledgment}

This research has been supported by the Czech Science Foundation, under project No 15-05791S.

\section{References}

1. J. Zhao, J.J. Zheng, G.F. Peng, K. van Breugel, Cement Concrete Res., 64, 64 (2014)

2. L.T. Phan, N.J. Carino, ACI Mater. J., 99, 54 (2002)

3. F.J. Ulm, P. Acker, M. Lévy, J. Eng. Mech., 125, 283 (1999)

4. S. Sanchayan, S.J. Foster, Mater. Struc., 49, 769 (2016)

5. K. Sakr, E. El-Hakim, Cement Concrete Res., 35, $590(2005)$

6. O. Arioz, Fire Saf. J., 42, 516 (2007)

7. J. Xiao, G. Konig, Fire Saf. J., 39, 89 (2004)

8. K.D. Hertz, Fire Saf. J. 38, 103 (2003)

9. Y. Fu, L. Li, Mater. Structur., 44, 361 (2011)

10. G.A. Khoury, Prog. Struct. Eng. Mater., 2, 256 (2000)

11. A.H. Akca, N.O. Zihnioglu, Constr. Build Mater., 44, 317 (2013)

12. G.F. Peng, Z.S. Huang, Constr. Build. Mater., 36, 593 (2008)

13. Q. Ma, R. Guo, Z. Zhao, Z. Lin, K. He, Constr. Build. Mater., 93, 371 (2015)

14. W.M. Lin, T.D. Lin, L.J. Power-Couche, ACI Mater., 93, 239 (1996)

15. M. Benes, R. Stefan, Int. J. Heat. Mass. Tran., 85, 110 (2015)

16. Z. Pavlík, M. Keppert, M. Pavlíková, J. Žumár, J. Fořt, R. Černý, Cement Wapno Beton, 2, 67, (2014)

17. Z. Pavlík, A. Trník, M. Keppert, M. Pavlíková, J. Žumár, R. Černý, Int. J. Thermophys., 35, 767, (2014)

18. Z. Pavlík, J. Fořt, M. Záleská, M. Pavlíková, A. Trník, I. Medved', M. Keppert, P.G. Koutsoukos, R. Černý, J. Clean. Prod., 112, 409 (2016)
19. I. Netinger, I, Kesegic, I. Guljas, Fire Saf. J., 46, 425 (2011)

20. L.P: Estevez, Thermochemica Acta, 518, 27 (2011)

21. A. Yazdani, H.R. Rezaie, H. Ghassai, J. Ceram. Process Res., 11, 348 (2010) 